\title{
Central neuropathic pain
}

\author{
Dores neuropáticas centrais \\ João Batista Santos Garcia', José Osvaldo Barbosa Neto², Edson José Amâncio ${ }^{3}$, Erich Talamoni Fonoff de Andrade ${ }^{4}$
}

DOI 10.5935/1806-0013.20160052

\section{ABSTRACT}

BACKGROUND AND OBJECTIVES: Central pain, classified as neuropathic, is defined as a painful syndrome caused by injury to central nervous system structures. This is one of the most complexes, intriguing and difficult to treat syndromes. This study aimed at promoting a narrative review including the concept of central pain, its intercurrent symptoms which are important for the diagnosis, and different available treatments, indications, results and complications.

CONTENTS: Relevant articles available in Medline, Scielo, Cochrane Library and Pubmed databases in the last 10 years were selected by means of keywords: chronic neuropathic pain, central neuropathic pain, central pain.

CONCLUSION: Central painful syndrome is diagnosed by means of neurological clinical evaluation. It is often refractory to clinical and neuromodulatory treatment, its management should be multimodal and allow for rehabilitation. Keywords: Central neuropathic pain, Central pain, Chronic neuropathic pain.

\section{RESUMO}

JUSTIFICATIVA E OBJETIVOS: A dor central, classificada como neuropática, é definida como uma síndrome dolorosa que decorre da lesão de estruturas no sistema nervoso central. Trata-se de uma das síndromes dolorosas mais complexas, intrigantes e de difícil tratamento. O objetivo deste estudo foi promover uma revisão narrativa que inclui desde o conceito de dor central, seus sintomas intercorrentes importantes no diagnóstico; e diversos tratamentos disponíveis, indicaçôes, resultados e complicaçôes.

CONTEÚDO: Foi realizada uma seleção de artigos relevantes disponíveis nas plataformas Medline, Scielo, Biblioteca Cochrane e Pubmed nos últimos 10 anos, por meio dos descritores: dor crônica neuropática, dor neuropática central, dor central.

CONCLUSÁO: A síndrome dolorosa central tem seu diagnóstico realizado por meio do exame clínico neurológico. É frequentemente refratária ao tratamento clínico e neuromodulatório e, portanto, deve ser multimodal e permitir a reabilitação.

Descritores: Dor central, Dor crônica neuropática, Dor neuropática central.

\section{INTRODUCTION}

Central pain (CP), classified as neuropathic pain (NP), is defined as painful syndrome induced by central nervous system (CNS) structure injury ${ }^{1}$. It is one of the most complexes, intriguing and difficult to treat painful syndromes which may originate from any CNS injury, such as vascular (ischemia or hemorrhage), ischemic or hemorrhagic stroke (IS, HS), infectious (abscess, encephalitis, myelitis), demyelinating multiple sclerosis (MS), traumatic (brain or spinal cord) or neoplastic. However, in most cases it is induced by stroke, MS and spinal cord injury².

1. Universidade Federal do Maranháo, Hospital do Câncer do Maranhão, Serviço de Dor e Cuidados Paliativos, São Luís, MA, Brasil.

2. Universidade de Sáo Paulo, Faculdade de Medicina, Escola de Cancerologia Celestino Bourroul da Fundaçáo Antônio Prudente, Departamento de Terapia Antálgica, Cirurgia Funcional e Cuidados Paliativos, São Paulo, SP, Brasil

3. Universidade Federal de Sáo Paulo, Departamento de Neurocirurgia, São Paulo, SP, Brasil.

4. Universidade de Sáo Paulo, Faculdade de Medicina, Departamento de Neurologia, Sáo Paulo, SP, Brasil.

Conflict of interests: none - Sponsoring sources: none.

\section{Correspondence to:}

Av. Sáo Marcos, n4/502. Ponta da Areia.

65077-310 São Luís, MA, Brasil

E-mail: jbgarcia@uol.com.br

(c) Sociedade Brasileira para o Estudo da Dor

\section{SIGNS AND SYMPTOMS}

$\mathrm{CP}$ diagnosis is particularly challenging in patients with neurological impairment and requires differential diagnosis from musculoskeletal pain or peripheral neuropathies.

In general, descriptors are similar to those of peripheral neuropathies. Complains of burning, painful cold, tingling, pricking, jumping, stabbing, pressing and sensation of constriction are common. In addition, there is also chronic itching, which is considered equivalent to pain. Also, one should take into account that some of these descriptors may reflect musculoskeletal pain presentations in patients with previous neurological impairment. So, the presence or absence of already described signs and symptoms does not confirm or rule out the diagnosis ${ }^{3}$. Differently from already described signs and symptoms, the presence of allodynia (painful sensation evoked by painless stimulus) and hyperalgesia (exaggerated pain sensation evoked by low intensity painful stimulus), is more specific for NP, however their presence is less common in central pain.

Central NP may also be described as continuous or paroxysmal, it may be spontaneous or evoked or may manifest as a combination of such characteristics, which is the most frequent presentation. It may also be described as superficial, deep or mixed. In general, its intensity is described as moderate to severe, being sometimes limiting ${ }^{2}$. Mood changes, present in $87 \%$ of patients, and sleep disorders present in $50 \%$ of patients, add high morbidity to $\mathrm{CP}^{4,5}$.

During patients' evaluation, one should look for changes in sensitivity to pricking and temperature. Since for the development of CP it is mandatory to have spinothalamic tract dysfunction (pathway responsible for the conduction of such stimuli), the absence of changes in these functions virtually rule out the diagnosis of $\mathrm{CP}^{2}$. It is important to remember that to be classified as central, pain must be contained in the area affected by CSN injury; however, it is not mandatory that the whole area is involved. It is possible that other body areas have musculoskeletal pain induced by the overload to which they are submitted to compensate the affected limb.

The differentiation between peripheral and central NP should be done as from clinical history data added to physical evaluation and sometimes to complementary exams, such as electroneuromyography (ENM) and magnetic resonance (MRI), directed to injury topography.

Scales to identify NP patients are useful, and among those most commonly used and validated to the Portuguese language there are the DN4 Questionnaire and LANNS Pain Scale (Leeds Assessment of Neuropathic Symptoms and Signs) ${ }^{6}$. One should take into account that these scales are limited, both in sensitivity and specificity, which vary between $70 \%$ and $80 \%{ }^{2}$.

Central pain varies a lot at onset of symptoms and may be present at injury moment or may take some weeks, months or even years to manifest ${ }^{2}$. This is especially common in IS, MS and spinal cord injury, being that the latter may induce pain up to five years after initial injury $y^{7-9}$

Table 1 shows data on chronologic onset of central pain.

\section{PATHOPHYSIOLOGY}

As described, cortical spinothalamic pathway injury, which is the pathway transmitting pain and temperature sensation, is critical for the development of post-stroke and post-spinal injury central pain ${ }^{10}$. However, sensory loss induced by injuring this pathway is not enough to produce the syndrome, which is notable in patients with some form of CNS injury and who do not develop CP.

New evidences suggest that hypersensitivity secondary to denervation of surviving spinothalamic tract axons has a triggering role in the onset of pain, especially when this hypersensitivity appears in axons transmitting thermal sensation (especially cold) $)^{7,11}$. Evidences of the importance of these hypersensitive pathways as pain generators may be shown by decreased pain 
Table 1. Chronologic onset of central pain after stroke. Adapted ${ }^{2}$

\begin{tabular}{|c|c|c|c|c|c|c|c|}
\hline Type of stroke & At stroke (\%) & $\begin{array}{c}\text { Within } 1 \text { month } \\
(\%)\end{array}$ & $\begin{array}{l}\text { Within 1-3 } \\
\text { months (\%) }\end{array}$ & $\begin{array}{l}\text { Within 4-6 } \\
\text { months (\%) }\end{array}$ & $\begin{array}{l}\text { Within 1-6 } \\
\text { months (\%) }\end{array}$ & $\begin{array}{l}\text { Within 6-12 } \\
\text { months (\%) }\end{array}$ & $\begin{array}{c}\text { One year later } \\
(\%)\end{array}$ \\
\hline All types ${ }^{7}$ & NR & 62 & NR & NR & 19 & 19 & NR \\
\hline Thalamic stroke ${ }^{8}$ & 18 & 38 & 15 & 12 & NR & 6 & 11 \\
\hline Lateral thalamic infarction ${ }^{9}$ & 14 & 29 & 43 & 7 & NR & 7 & NR \\
\hline
\end{tabular}

below spinal injury level after spinal anesthesia ${ }^{12}$.

Another relevant mechanism for the development of post-stroke and postspinal injury $\mathrm{CP}$ is dishinibition of medial thalamus as a consequence of lateral thalamus injury and consequent destruction of Gabaergic neurons in ventral postero-lateral thalamic nucleus. Sensory information brought by surviving and recovering pathways may be interpreted in the CNS as painful sensation ${ }^{2,9}$. However, while in post-stroke this abnormal hyperreactive thalamus may be understood as pain-generating center, in spinal injuries thalamic changes are consequence of central sensitization caused by the dishinibition of surviving ascending nociceptive pathways at spinal injury level².

\section{SPECIFIC PAINFUL SYNDROMES}

\section{Pain after stroke}

Stroke is one of the major causes of death worldwide. Annually, approximately 16 million people are affected by this disease and from them, up to six million die. In Brazil, approximately 68 thousand deaths are registered per year as a consequence of stroke, which places it as major cause of death in this country. Still, physical incapacity and chronic pain tend to be reality for a large part of survivors ${ }^{13}$.

Since stroke is the most prevalent CNS injury (more frequent than multiple sclerosis or spinal cord injuries, for example), post-stroke pain is the most common form of CP pain, affecting 2 to $8 \%$ of patients with the disease ${ }^{7}$. This incidence is even higher among patients evolving with sensory and/or motor deficiency, being approximately $18 \%{ }^{14}$.

The risk of developing CP is similar for IS and HS, however injury topography seems to be more relevant for its development, especially the thalamic region ${ }^{2}$. Thalamic infarction is responsible for 25 to $33 \%$ of poststroke $\mathrm{CP}$, being more frequent when involving postero-ventral thalamic nucleus $^{7,8}$. Also, patients between 58 and 67 years of age seem to be in higher risk of developing CP than older patients, and data suggest that right brain infarctions are at higher risk of coursing with $\mathrm{CP}^{2}$.

\section{Pain after spinal cord injury}

This syndrome is more frequent among young male patients, mean age of approximately 38 years at injury time, differently from post-stroke $\mathrm{CP}^{15}$. In Brazil, the incidence of spinal cord injury is of 40 new cases/year/million inhabitants (that is, approximately 6 to 8 new cases per year), being more frequent among males (86\%) aged between 20 and 40 years (64\%), more commonly affecting thoracolumbar segment (64\%), and most common causes are falls, followed by car accidents, gunshot wound, diving in shallow waters and other aggressions ${ }^{16,17}$.

Patients with spinal cord injury may develop pain of different origins, such as musculoskeletal (muscle spasms, for example); visceral (neurogenic bladder, for example); different nociceptive pains (pressure sores, for example); peripheral neuropathic pain induced by injury of nervous roots at injury or spinal cord dorsal horn level; and NP below spinal cord injury level, being this considered $\mathrm{CP}^{2}$. Understanding spinal cord injury level is important for diagnostic definition, because for pain to be considered central, by definition it must affect regions below spinal cord injury.

It is estimated that up to $31 \%$ of spinal cord injury patients shall evolve with CP within 12 months after trauma, and additional $31 \%$ shall develop $\mathrm{NP}$ at injury level, being this more common in the first months after injury and with higher chance of resolution along time ${ }^{18}$. Neuromuscular pain, although less severe, is very frequent, being present in up to $70 \%$ of patients, and should be considered during these patients' treatment and rehabilitation ${ }^{5}$.

Negative data is that pain related to spinal cord injury tends to be difficult to resolve, with a minority of patients evolving with improved symptoms along time. A study has shown that only $6 \%$ of patients had pain improvement, while half the patients have reported worsening of pain, both in intensity and frequency, which shows the severity of this disease ${ }^{19}$.

\section{Pain related to multiple sclerosis (MS)}

MS is a chronic and progressive disease, more common in youngsters, of autoimmune etiology where demyelination plaques induce brain and spinal cord dysfunction. It is estimated that, worldwide, 2.5 million people have MS. In Brazil, data from the Brazilian Association of Multiple Sclerosis indicate a prevalence of 5-20 MS patients for every 100 thousand inhabitants $^{20}$.

There are different forms of MS; however, remittent-recurrent form occurs in up to $85 \%$ of cases and is translated by the sub-acute onset of neurological dysfunction, with subsequent progressive improvement, and remains for periods where there is no neurological deterioration. In these cases, there might even be evolution for the secondary progressive form where neurological deterioration is present without distinction of attacks and may affect up to $80 \%$ of these patients. Also, up to $10 \%$ of patients start with primary progressive form and $5 \%$ are diagnosed with recurrent-progressive form. However, regardless of the type of MS, in general patients accumulate different neurological dysfunction levels, determining the progressive character of the diseases ${ }^{20}$. Figure 1 shows the prevalence of the disease by countries.

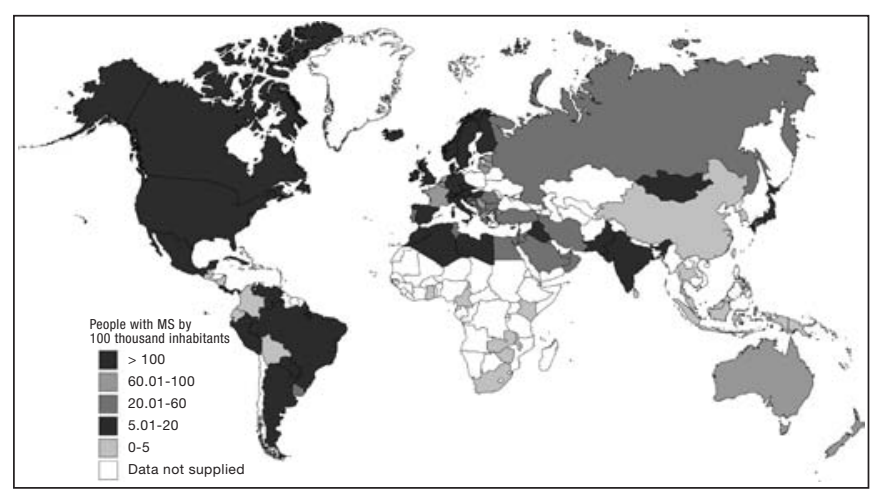

Figure 1. Prevalence of multiple sclerosis by country in 2013

Brazilian Association of Multiple Sclerosis (ABEM) (internet homepage). Multiple sclerosis Atlas in 2013 Access in 05/01/2016. Available in: http://abem.org.br/wpcontent/uploads/2016/02/Atlas_EM_2013_FINAL_ABEM_baixa.pdf

Chronic pain is very prevalent in MS, varying between 29 and $80 \%$, being that up to $75 \%$ of patients refer pain along the month when the diagnosis is made ${ }^{2}$. Similarly to already described painful syndromes, recurrent MS pain has multifactorial origin, such as immobilism, tonic spasticity (6 to $19 \%)$ and bed sores. Baseline disease treatment itself induces pain, since interferon beta triggers myalgia crises and pain at application site. Peripheral NP is frequent and, in some cases, is the symptom responsible for triggering diagnostic investigation. Trigeminal neuralgia (TN) has prevalence of up to $6 \%$ in MS patients and, from these, $14 \%$ had this symptom as primordial for the diagnosis.

MS-related TN in general affects younger patients and may be bilateral (12\% to $28 \%$ ); it seldom affects V1 (ophthalmic trigeminal branch). When there is bilateral TN, MS diagnosis should be presumed and investigated ${ }^{2,21}$. Lhermitte signal is strongly associated to MS diagnosis and is present at 
some moment of disease evolution in up to $41 \%$ of cases ${ }^{22}$. This symptom is a paroxysmal sensation of shock along the spine (and sometimes limbs), triggered by binding the neck. This is consequence of an acute or sub-acute episode of demyelination in the posterior column of the cervical spine, and in general resolves in few weeks. It is important to stress that, since spinothalamic tract is not affected, Lhermitte signal is not considered symptom of central pain ${ }^{2}$.

Seldom CP is the initial symptom, affecting just $1-3 \%$ of cases. It has prevalence of 12 to $28 \%$ throughout patient's whole life and in general starts one year after neurological symptoms onset in the affected area (loss of pain and temperature sensation), and may occur in different simultaneous sites. It is in general associated to progressive forms, advanced disease, older patients and patients with more severe dysfunction level ${ }^{21}$.

\section{CONSERVATIVE TREATMENT}

$\mathrm{CP}$ is difficult to treat and, as a general rule, total pain control is improbable. The difficulty to control the symptom sometimes makes treatment frustrating both for patients and physicians following them. For this reason, treatment objectives (such as focusing on function gain instead of on pain intensity) should be clearly discussed with patients since the first meeting. So, by means of multimodal pharmacological strategy associated to non-pharmacological therapies it is possible to get better quality of life for patients and have them acquiring functional gain.

It is important to stress that mild pain intensity decrease, such $30 \%$ decrease ( 2 points in the numerical verbal scale from $0-10)$, had positive correlation with sensible clinical improvement reports by patients ${ }^{23}$. That is, stubborn search for eliminating pain is not necessary, and even inadvisable, because this may lead the clinician to increase analgesic doses to a point where adverse effects become factors limiting quality of life of patients.

Before discussing pharmacological therapy, some specific aspects of $\mathrm{CP}$ patients should be reinforced. These patients have as consequence of their baseline disease different levels of neurological impairment, be it physical, behavioral and/or of speech, so they might have less tolerance to drugs the effects of which include dizziness, ataxia, mental confusion or sedation. Also, these patients in general are submitted to a wide array of drugs to treat CNS injury, which places them at relevant risk for severe pharmacological interactions. Additionally, these patients in general have depression and anxiety which should be taken into consideration at treatment planning.

Generally speaking, pharmacological therapy for CP includes the same classes of drugs used to treat NP, such as anticonvulsants, tricyclic antidepressants, dual antidepressants and possibly opioids. Table 2 summarizes evidences with regard to pharmacological treatment for central pain.

Sometimes, a potent analgesic is necessary as adjuvant to treatment, especially if other causes of pain, such as musculoskeletal, are adding to clinical presentation. In this scenario, a possible opioid would be methadone, which has pharmacological characteristics (NMDA block and norepinephrine and serotonin reuptake inhibition) which make it more adequate for such cases ${ }^{24,25}$. Cannabinoids were particularly effective for MS patients, both to treat pain and spasticity ${ }^{26,27}$.

In addition to pharmacological therapy, it is critical the early beginning of physical rehabilitation associated to analgesic physiotherapy. Non-pharmacological measures, such as mirror therapy and virtual reality immersion therapy are recommended for patients with post-stroke pain and MS-related pain, and transcranial stimulation in patients after spinal cord injury is an example of approaches indicated as treatment adjuvant ${ }^{28}$.

\section{SURGICAL TREATMENT OF CENTRAL NEUROPATHIC PAIN}

The development of drugs with higher potency and selectivity, and more adequate pharmacokinetics and pharmacodynamics, made indications of surgical procedures for pain control naturally less frequent. Surgical procedures, however, are still useful for a considerable number of patients with pain refractory to drug therapy, or even due to adverse effects preventing their use.

Ablative procedures aim at interrupting pain pathways by selective injury of structures of peripheral nerves, nervous roots and ganglia, medullary cords and ascending pathways and structures of the brain, such as thalamus or midbrain nuclei. Limbic system structure injury also acts to decrease cognitive and emotional components associated to pain, which cause distress to individuals. Some more common procedures as described below.

DREZotomy or Lissauer tract/spinal cord posterior horn (SCPH) injury

It consists of lysis, by radiofrequency, of Lissauer tract and gray matter of spinal cord posterior horn, where there is neuronal hyperactivity in cases of pain by deafferentation of spasticity. It is performed to treat phantom limb pain, pain resulting from actinic plexular, oncologic and traumatic neuropathies, post-herpetic neuralgia, myelopathic pain and pain due to cauda equina injury and spasticity, pain by nervous roots avulsion, NP or nociceptive pain oligocircunscribed by deafferentation.

This procedure decreases nociceptive pathways hyperactivity of spinal cord ascending tracts because it inactivates hyperactive neurons of SCPH laminae I, II, III, IV, V and VI, and Lissauer tract, which are involved in mechanisms of facilitation and SCPH neurons activity inhibition, as well as ascending pathways which traffic through the spinal cord postero-lateral quadrant. This allows changing the balance between excitatory and inhibitory pathways of deafferented segmental neuronal circuits ${ }^{29}$.

Lissauer tract and SCPH injury is more effective and safe when indicated to treat patients with extensive deafferentation areas, such as in cases of brachial plexus roots avulsion, actinic plexular neuropathy, segmental pain in paraplegic patients with myelopathy or with cauda equina and conus injury ${ }^{29}$.

\section{Mesencephalotomy}

This procedure aims at interrupting spinoreticulo-thalamic pathways involved in the maintenance of the unpleasant sensation in NP patients. Spiegel \& Wycis $^{30}$ were the first to perform mesencephalotomy to treat CP. There is long-lasting improvement in $77.8 \%$ of NP patients submitted to mesencephalotomy or baseline thalamotomy during periods varying from 2 months to 8 years.

Mesencephalotomy initially or partially relieves encephalic CP in $65 \%$ of patients. In the long term, there is 20 to $66.7 \%$ relief and improvement of $30 \%$. Mortality is $7.4 \%$. Best results are obtained when injuries are performed in posterior commissure plane, where very frequently it generates oculomotor changes, contrasting with injuries to the superior colliculus where these complications are present in 23 to $54 \%$ of cases. Tasker ${ }^{31}$ has observed pain relief in $50 \%$ of his $10 \mathrm{CP}$ cases submitted to mesencephalic tratotomy. In nine cases there has been temporary improvement. None had severe complications.

Others have not observed the efficacy of such method. Shieff \& Nashold ${ }^{32}$ have concluded that CP of thalamic syndrome, of lateral bulbar syndrome, of post-cordotomy dysesthesia, of phantom pain by brachial plexus roots

Table 2. Summary of scientific evidences for pharmacological therapy for most common types of central pain. Adapted

\begin{tabular}{|c|c|c|c|c|c|}
\hline Drugs & Dose (min-max) & Effective dose (mean) & Post-stroke pain & Post-spinal cord injury pain & MS-related pain \\
\hline Gabapentin & $300-3600 \mathrm{mg} / \mathrm{d}$ & $1800 \mathrm{mg} / \mathrm{d}$ & $?$ & Conflicting data & $?$ \\
\hline Pregabalin & $150-600 \mathrm{mg} / \mathrm{d}$ & $450 \mathrm{mg} / \mathrm{d}$ & Conflicting data & ++ & $?$ \\
\hline Lamotrigine & $25-400 \mathrm{mg} / \mathrm{d}$ & $200-400 \mathrm{mg} / \mathrm{d}$ & + & + & $?$ \\
\hline Amitriptyline & $25-150 \mathrm{mg} / \mathrm{d}$ & $75 \mathrm{mg} / \mathrm{d}$ & + & Conflicting data & $?$ \\
\hline Duloxetine & $30-120 \mathrm{mg} / \mathrm{d}$ & $60 \mathrm{mg} / \mathrm{d}$ & $?$ & $?$ & $?$ \\
\hline Cannabinoids & - & - & $?$ & $?$ & ++ \\
\hline
\end{tabular}

$?=$ without randomized clinical trials; $+=$ favorable clinical trials; $++=$ multiple favorable clinical trials; MS = multiple sclerosis 
pullout and of post-herpetic neuralgia may be relieved in $50 \%$ of cases with stereotaxic mesencephalotomy.

Most common complications of mesencephalotomy are sleepiness and ocular motility dyssinergy, in general temporary. Complication which may become permanent in $30 \%$ of patients is paresis of conjugated gaze up.

\section{Thalamotomy}

This procedure consists of the injury of spinothalamic and paleospinothalamic units by means of nonspecific thalamic nuclei injury. It is indicated in cases of nociception and deafferentation-induced pain in broad body regions, especially when located in the cranio-cervical and brachial segments and in patients with contraindication for cordotomy $y^{33}$.

In the past, thalamotomy of median dorsum nucleus and anterior thalamic nuclei was widely used by several authors aiming at changing emotional abnormalities associated to pain. However, due to complications, especially in the mental sphere, this technique has been abandoned ${ }^{33}$.

Injuries have to be extensive and located in the center-median nucleus, parafascicular, limitans and thalamic intralaminar nuclei (unspecific thalamic nuclei) involved in pain maintenance. So, injuries shall involve paelospinothalamic pathways and units ${ }^{33}$.

Thalamotomy temporarily relieves NP (peripheral neuropathies, myelopathies and encephalopathies) in 40 to $70 \%$ of cases, and cancer pain in $90 \%$. Results, however, are often unsatisfactory in the long term. When injuries are small, there is improvement in less than $30 \%$ of cases. Best results seem to be observed in cases of bilateral injuries ${ }^{33}$.

\section{Motor cortex stimulation}

Motor cortex stimulation (MCS) is promising, especially to treat trigeminal $\mathrm{NP}$ and post-stroke CP syndromes, such as thalamic pain syndrome, brachial plexus avulsion, among others. Since early experiments, motor cortex stimulation has produced better results as compared to sensory cortex stimulation. Several case sequences have shown good MCS results to treat untreatable painful syndromes, including post-stroke pain, phantom limb pain, spinal cord injury pain, post-herpetic neuralgia and limbs and face NP.

Most studies involving MCS focuses its use in post-stroke and trigeminal neuropathy, for which there are few effective treatments. Post-stroke pain responds well to MCS, because approximately two third of patients have satisfactory relief. MCS results to treat trigeminal neuropathic pain are very interesting, because they have shown that 75 to $100 \%$ of patients had good or excellent pain relief ${ }^{34}$.

Although most studies have not reported adverse events after motor cortex stimulation, some complications were described. Among described there are intracranial hemorrhage, infection and permanent neurological deficits. Seizures induction was also reported depending on stimulation intensity and frequency which favor such events when they get close to motor threshold. However, in general there is no progression or development of epilepsy ${ }^{34,35}$.

To date, there are no prospective studies showing final conclusions on general and specific efficacy of MCS. Literature has divergent opinions with regard to surgical technique, stimulation parameters programming and patients' selection. However, MCS seems to be a relatively safe and effective neuromodulatory procedure for selected patients ${ }^{35}$.

\section{Deep brain stimulation (DBS)}

In the 1970s, other authors (Mazars, 1973) have reported the first experience with chronic stimulation of thalamic sensory nuclei to treat $\mathrm{NP}^{36}$. Other authors have reported long term success with somesthetic thalamic stimulation and later the target has shifted to periaqueductal gray matter (PAG) and periventricular gray matter (PVG) of the III ventricle ${ }^{37}$.

Recently, a meta-analysis was carried out to determine the efficacy of DBS to treat chronic pain. Evaluated articles have shown long term results in a total of 1114 patients. From these, $561(50 \%)$ had long term pain relief with DBS. Rates of good long term results have varied between 19 and $79 \%$, showing efficacy loss in the long term. A total of 711 patients had NP, of whom $296(42 \%)$ had sustained long term relief. From 443 patients with nociceptive pain, $272(61 \%)$ had long term success ${ }^{35}$.

Among deep brain stimulation complications, intracranial hemorrhage is the most significant and potentially severe. It may occur at electrode insertion or removal. The incidence of hemorrhage varies between 1.9 and
4.1\%. There have been permanent neurological deficits in 14 out of 649 registered patients, with incidence of such complications varying from 2.0 to $3.4 \%$. Mortality related to this procedure is low, varying from 3.3 to $13.3 \%{ }^{35}$.

DBS has shown its best results to treat cluster headache and nociceptive syndromes, such as chronic low back pain; while encephalic post-stroke central pain syndromes, post-herpetic neuralgia and myelopathic pain have poorly responded to DBS. DBS should only be considered after failure of conservative treatments, including less invasive nerve stimulation methods $s^{35}$.

\section{Spinal infusion of analgesic drugs}

In the last decade, this trend was partially reverted with the use of implantable systems for analgesic drugs release (in general opioids) in the CNS (intraventricular, cisternal and lumbar spine), associated to difficulty of qualifying professionals to perform stereotaxis.

Pumps have a drug reservoir which gives variable autonomy to patients, depending on the dose and its use. They may be driven by permanent gases expansion pressure and by computerized electronic pumping, telemetrically commanded. They may release drugs in the spinal, cisternal and intraventricular space. Spinal release is the most effective because the dose needed to control pain is the lowest possible and with this, in general, there is no drug in systemic circulation ${ }^{37}$.

Results were excellent in $50 \%$ of cases of central NP and good in remaining cases, during a follow up period with mean duration of 21 months; adverse effects were uncommon and there has been no infection or operational problems with the implanted system. In Brazil, results have been reported as satisfactory in different types of NP refractory to oral drugs, reaffirming the method to treat painful syndromes of difficult clinical and even surgical control ${ }^{37,38}$. However, there are adverse effects from those directly related to drug effect on central receptors to effect on hypothalamic-pituitary axis with hormonal and bone metabolism changes.

\section{CONCLUSION}

$\mathrm{CP}$ is very frequent in patients suffering some type of CNS injury, however its diagnosis is difficult and its treatment is challenging. It is necessary to find a balance between the best possible analgesia and the maintenance of desirable cognitive and functional capacity, providing good quality of life in spite of limitations imposed by neurological dysfunction.

\section{REFERENCES}

1. Greenspan JD, Treede R, Tasker RR, Lenz FA. Central Pain States. In: Fishman SM, Ballantyne JC, Rathmell JP, editors. Bonica's Management of Pain $4^{\text {th }}$ ed. Lippincott: Williams and Wilkins; 2010. 357-74p. Watson JC, Sandroni P. Central neuropathic pain syndromes. Mayo Clin Proc. 2016;91(3):372-85. Watson JC, Sandroni P. Central neuropathic pain syndromes. Mayo Clin Proc. 2016;91(3):372-85.
Putzke JD, Richards JS, Hicken BL, Ness TJ, Kezar L, DeVivo M. Pain classification following spinal cord injury: the utility of verbal descriptors. Spinal Cord. 2002;40(3):118-27.

Jönsson AC, Lindgren I, Hallström B, Norrving B, Lindgren A. Prevalence and intensity of pain after stroke: a population based study focusing on patients' perspectives. J Neurol Neurosurg Psychiatry. 2006;77(5):590-5.

5. Siddall PJ, McClelland JM, Rutkowski SB, Cousins MJ. A longitudinal study of the prevalence and characteristics of pain in the first 5 years following spinal cord injury. Pain. 2003;103(3):249-57.

6. Schestatsky P, Félix Torres V, Chaves ML, Câmara-Ehlers B, Mucenic T, Caumo W, et al. Brazilian Portuguese validation of the Leeds assessment of neuropathic symptoms and signs for patients with chronic pain. Pain Med. 2011:12(10):1544-50.

7. Andersen G, Vestergaard K, Ingeman-Nielsen M, Jensen TS. Incidence of central post-stroke pain Pain. 1995;61(2):187-93.

8. Nasreddine ZS, Saver JL. Pain after thalamic stroke: right diencephalic predominance and clinical features in 180 patients. Neurology. 1997;48(5):1196-9.

Kumar G, Soni CR. Central post-stroke pain: current evidence. J Neurol Sci. 2009;284(1-2):10-7. . Finnerup NB, Johannesen IL, Fuglsang-Frederiksen A, Bach FW, Jensen TS. Sensory function in spinal cord injury patients with and without central pain. Brain. 2003;126(pt 1):57-70.

11. Wasner G, Lee BB, Engel S, McLachlan E. Residual spinothalamic tract pathways predict development of central pain after spinal cord injury. Brain. 2008;131(pt 9):2387-400

12. Loubser PG, Donovan WH. Diagnostic spinal anaesthesia in chronic spinal cord injury pain. Paraplegia. 1991;29(1):25-36.

13. Portal Brasil [homepage da internet]. Acidente vascular cerebral (AVC). Acesso em 30/04/2016 Disponível em http://www.brasil.gov.br/saude/2012/04/acidente-vascular-cerebral-avc.

14. Klit H, Finnerup NB, Andersen G, Jensen TS. Central poststroke pain: a population-based study. Pain. 2011;152(4):818-24

15. National Spinal Cord Injury Statistical Center (homepage da internet. Spinal cord injury (SCI) facts and figures at a glance. Acessado em 30/04/. Disponivel em: https://www.nscisc.uab.edu/PublicDocuments/reports/pdf/Facts\%202011\%20Feb\%20Final.pdf.

16. Ministério da Saúde (homepage da internet). Diretrizes de atençăo a pessoa com lesão medular. Acesso em 01/05/2016. Disponivel em: http://bvsms.saude.gov.br/bvs/publicacoes/diretrizes_atencao_pessoa_lesao_medular.pdf.

17. Campos MF, Ribeiro AT, Listik S, Pereira CA, Andrade SJ, Rapoport A. Epidemiologia do traumatismo da coluna vertebral. Rev Col Bras Cir. 2008;35(2):88-93. 
18. Finnerup NB, Norrbrink C, Trok K, Piehl F, Johannesen IL, Sorensen JC, et al. Phenotypes and predictors of pain following traumatic spinal cord injury: a prospective study. J Pain. 2014;15(1):40-8.

19. Störmer S, Gerner HJ, Grüninger W, Metzmacher K, Föllinger S, Wienke C, et al. Chronic pain/dysaesthesia in spinal cord injury patients: results of a multicenter study. Spinal Cord. 1997;35(7):446-55.

20. Associaçăo Brasileira de Esclerose Múltipla (ABEM) (homepage da internet). Atlas em Esclerose Múltipla em 2013. Acesso em: 01/05/2016. Disponível em: http://abem.org.br/wp content/uploads/2016/02/Atlas_EM_2013_FINAL_ABEM_baixa.pdf.

21. Österberg A, Boivie J, Thuomas KA. Central pain in multiple sclerosis--prevalence and clinical characteristics. Eur J Pain. 2005;9(5):531-42

22. Nick ST, Roberts C, Billiodeaux S, David DE, Samanifekri B, Sahraian MA, et al. Multiple sclerosis and pain. Neurol Res. 2012;34(9):829-41.

23. Farrar JT, Young JP Jr, LaMoreaux L, Werth JL, Poole RM. Clinical importance of changes in chronic pain intensity measured on an 11-point numerical pain rating scale. Pain. 2001;94(2):149-58.

24. Trafton JA, Ramani A. Methadone: a new old drug with promises and pitfalls. Curr Pain Headache Rep. 2009;13(1):24-30.

25. McNicol ED, Midbari A, Eisenberg E. Opioids for neuropathic pain. Cochrane Database Syst Rev. 2013;29;8:CD006146

26. Svendsen KB, Jensen TS, Bach FW. Does the cannabinoid dronabinol reduce central pain in multiple sclerosis? Randomized double blind placebo controlled crossover trial. BMJ. 2004;329(7460):253-60.

27. Ungerleider JT, Andyrsiak T, Fairbanks L, Ellison GW, Myers LW. Delta-9-THC in the treatment of spasticity associated with multiple sclerosis. Adv Alcohol Subst Abuse. 1987;7(1):39-50.

28. Castelnuovo G, Giusti EM, Manzoni GM, Saviola D, Gatti A, Gabrielli S, et al. Psychological treat- ments and psychotherapies in the neurorehabilitation of pain: evidences and recommendations from the Italian Consensus Conference on Pain in Neurorehabilitation. Front Psychol. 2016;7:115.

29. Thomas DG. Dorsal root entry zone (DREZ) thermocoagulation. Adv Tech Stand Neurosurg. 1986;15:99-114.

30. Spiegel EA, Wycis HT. Mesencephalotomy in treatment of intractable facial pain. AMA Arch Neurol Psychiatry. 1953;69(1):1-13.

31. Tasker RR. Mesencephalotomy for cancer pain. J Neurosurg. 1992;76(6):1052-3.

32. Shieff C, Nashold BS Jr. Stereotactic mesencephalotomy. Neurosurg Clin N Am. 1990;1(4):825-39.

33. Hitchcock ER, Teixeira MJ. A comparison of results from center-median and basal thalamotomies for pain. Surg Neurol. 1981;15(5):341-51

34. Fonoff ET, Hamani C, Ciampi de Andrade D, Yeng LT, Marcolin MA, et al. Pain relief and functional recovery in patients with complex regional pain syndrome after motor cortex stimulation Stereotact Funct Neurosurg. 2011;89(3):167-72.

35. Fontaine D, Hamani C, Lozano A. Efficacy and safety of motor cortex stimulation for chronic neuropathic pain: critical review of the literature. J Neurosurg. 2009;110(2):251-6.

36. Mazars G, Mérienne L, Ciolocca C. [Intermittent analgesic thalamic stimulation. Preliminary note]. Rev Neurol (Paris). 1973;128(4):273-9.

37. Lara NA Jr, Teixeira MJ, Fonoff ET. Long term intrathecal infusion of opiates for treatment of failed back surgery syndrome. Acta Neurochir Suppl. 2011;108:41-7.

38. Valverde-Filho J, da Cunha Neto MB, Fonoff ET, Meirelles Ede S, Teixeira MJ. Chronic spinal and oral morphine-induced neuroendocrine and metabolic changes in noncancer pain patients. Pain Med. 2015;16(4):715-25. 